\title{
Sonographic Monitoring of Midline Shift Predicts Outcome after Intracerebral Hemorrhage
}

\author{
Ines C. Kiphuth Hagen B. Huttner Lorenz Breuer Stefan Schwab \\ Martin Köhrmann \\ Department of Neurology, Universitätsklinikum Erlangen, Erlangen, Germany
}

\section{Key Words}

Intracerebral hemorrhage $\cdot$ Midline shift $\cdot$ Transcranial duplex sonography

\begin{abstract}
Background: Spontaneous intracerebral hemorrhage $(\mathrm{ICH})$ and the evolution of subsequent perihemorrhagic edema lead to midline shift (MLS), which can be assessed by transcranial duplex sonography (TDS). In this observational study, we monitored MLS with TDS in patients with supratentorial ICH up to day 14 after the ictus, and then correlated MLS with the outcome 6 months after hospital discharge. Methods: Sixty-eight patients with spontaneous ICH (volume $>20 \mathrm{~cm}^{3}$ ) were admitted during a 1-year period between April 2009 and April 2010. Sixty-one patients fulfilled the inclusion criteria and were eligible for analysis. TDS to measure MLS was performed upon admission and then subsequently, using serial examinations in 24-hour intervals up to day 14. Statistical tests were used to determine cut-off values for functional outcome and mortality after 6 months. $\boldsymbol{R} \boldsymbol{e}$ sults: The median National Institutes of Health Stroke Scale (NIHSS) score upon admission was 21 and the mean hematoma volume was $52 \mathrm{~cm}^{3}$. NIHSS score, functional outcome, hematoma volume and MLS were correlated in the examined patient cohort. ICH score upon admission, hematoma volume and the extent of MLS on days 1-14 were predictive
\end{abstract}

of functional outcome and death. Values of MLS showed two peaks, the first between day 2 and day 5 and the second between day 12 and day 14, indicating that edema progresses not only during the acute but also during the subacute phase. Depending on the time point, an MLS of 4.5-7.5 mm or greater indicated an impending failure of conservative therapy. An MLS of $12 \mathrm{~mm}$ or greater at any time indicated mortality with a sensitivity of $69 \%$, a specificity of $100 \%$ and positive and negative predictive values of 100 and $74 \%$, respectively. Conclusions: MLS seems to be a crucial factor for outcome after ICH. Apart from the hematoma volume itself, edema adds to the intracranial pressure. To monitor MLS in early patient management after ICH, TDS is a useful noninvasive bedside alternative, avoiding increased radiation exposure and repeated transportation of critically ill patients. Cut-off values may help to reliably predict functional outcome and treatment failure in patients undergoing maximal neurointensive therapy.

Copyright $\odot 2012$ S. Karger AG, Basel

\section{Introduction}

Spontaneous intracerebral hemorrhage (ICH) often leads to severe disability or death [1]. An early estimation of prognosis and the monitoring of treatment are essential in order to be able to inform patients and their

\section{KARGER}

Fax +4161306 1234 E-Mail karger@karger.ch www.karger.com

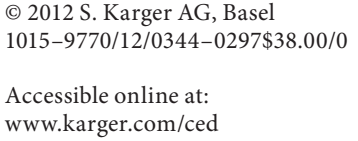

Dr. Ines Christine Kiphuth

Department of Neurology, Universitätsklinikum Erlangen

Schwabachanlage 6

DE-91054 Erlangen (Germany)

E-Mail ines-christine.kiphuth@uk-erlangen.de 
families and for decision-making regarding further treatment. Clinical outcome in patients with ICH varies, depending on a number of parameters, e.g. baseline hematoma volume, ventricular involvement, evolution of perihemorrhagic edema, age and blood glucose level [25]. In addition, midline shift (MLS) is a known prognostic factor for unfavorable outcome after ICH [6]. In clinical practice, repeated cranial computed tomography (CT) is often used to monitor MLS, causing increased radiation exposure and requiring repeated transportation of critically ill patients, which is associated with increased morbidity and mortality [7-9]. Transcranial duplex sonography (TDS) offers a noninvasive bedside alternative to radiologic methods. TDS measurements are valid for diagnosing and monitoring various neurological diseases including ICH [10-13]. In addition, TDS monitoring of the early dynamics of MLS reliably predicts early mortality and outcome in conservatively treated hemispheric ischemic stroke [14]. In contrast to ischemic stroke, MLS in ICH constitutes both the hematoma volume itself and the edema formation, which may make the prediction of outcomes more difficult. The objective of this study was to evaluate TDS as a monitoring method of MLS in patients with $\mathrm{ICH}$ who underwent maximal conservative treatment in the first 2 weeks after the ictus. Measurements were then correlated with mortality and functional outcome 6 months after hospital discharge. Cut-off values of MLS that best predicted mortality and outcome were calculated.

\section{Materials and Methods}

\section{Patients and ICH Management}

This study was performed in a specialized neurological intensive care unit at a tertiary university hospital (Erlangen, Germany). Patients with ICH (volume $>20 \mathrm{~cm}^{3}$ ) who were admitted between April 2009 and April 2010 were eligible. Exclusion criteria were an insufficient temporal bone window, hematoma evacuation and do-not-treat/resuscitate (DNT/DNR) orders at any time during the hospital stay. Patients who received DNT/DNR orders were excluded because the aim of this study was to predict functional outcome in patients with maximal neurointensive therapy and detect the MLS values that differentiate between survival and death in this patient cohort. ICH management was performed according to European recommendations [15]. Patients with intraventricular hemorrhage received extraventricular drainages according to institutional protocol and the discretion of the treating neurointensive care physician. Hematoma volume was calculated from CT imaging using the formula of ellipsoids [(length $\times$ width $\times$ height)/2], as previously described [16]. Hematoma growth was defined as an increase of $\geq 33 \%$ of the parenchymal hematoma volume compared to baseline [17].

\section{Outcome Assessment}

Functional outcome was assessed using the modified Rankin scale (mRS) at 6 months. The mRS was evaluated by a certified rater using a semistructured telephone interview with the patients or with their closest relatives [18]. Given that only ICHs with a volume $>20 \mathrm{~cm}^{3}$ were included in the study, functional outcomes were classified into favorable (mRS 0-2), acceptable (mRS 0-4) and unfavorable (mRS 5-6) outcomes. The cut-off point between acceptable and unfavorable outcomes was chosen according to the results of studies evaluating the opinions of the patients and their relatives on acceptable outcomes in a comparable intensive-care patient cohort $[19,20]$.

\section{Standard Protocol Approval, Registration and Patient}

Consent

Consent to participate in this study was obtained from all patients or their relatives/legal guardians. The study was approved by the local ethics committee.

Neurosonographic Methods

A single experienced examiner [I.C.K., trained in sonographic imaging of the intracranial ventricles by M.K., who is an ultrasound instructor of the highest level for the DEGUM (German Society for Ultrasound in Medicine) for 6 months before this study was initiated] performed TDS examinations with a phasedarray ultrasound system equipped with a $1.33 \mathrm{MHz}$ transducer (SIEMENS Acuson Antares) through the contralateral temporal bone window, as described before [14]. The probe was tilted approximately $10^{\circ}$ upward to scan axially with a penetration of $100-$ $140 \mathrm{~mm}$ and a dynamic range of $22 \mathrm{~dB}$ to visualize the contralateral skull bone. Contrast, image brightness and time-gain compensation were adjusted to receive the best image. The third ventricle was visualized at a depth of $60-80 \mathrm{~mm}$ and was identified by its parallel hyperechogenic margins and the surrounding hypoechogenic thalami [13]. The distance between the contralateral calotte and the margins of the third ventricle were measured in perpendicular lines bilaterally (fig. 1). The deviation from the presumed midline was measured by the equation (A - B)/2 (fig. 1). TDS was performed at the time of admission and in $24 \pm 3$-hour intervals for 14 days or until death or discharge.

\section{Statistics}

Statistical tests were two-sided, and the significance level was set at $\alpha=0.05$. The distribution of the data was assessed with the Kolmogorov-Smirnov test. Continuous and categorical variables are expressed as means and SDs, medians and ranges or percentages, as appropriate. Patients were grouped according to outcome and their age, sex, medical history, length of ventilation, National Institutes of Health Stroke Scale (NIHSS) score, mRS, hematoma volume and MLS were compared. Correlations between parameters and prediction of functional outcome using stepwise forward inclusion logistic regression models and receiver operating characteristic (ROC) analyses were calculated. All parameters that reached significance or at least showed a trend in univariate analyses were included in the multivariate analyses. For each time point of sonographic MLS measurement, a separate model was calculated. Analyses were conducted with the SPSS 17.0 software package (SPSS Inc., Chicago, Ill., USA). 


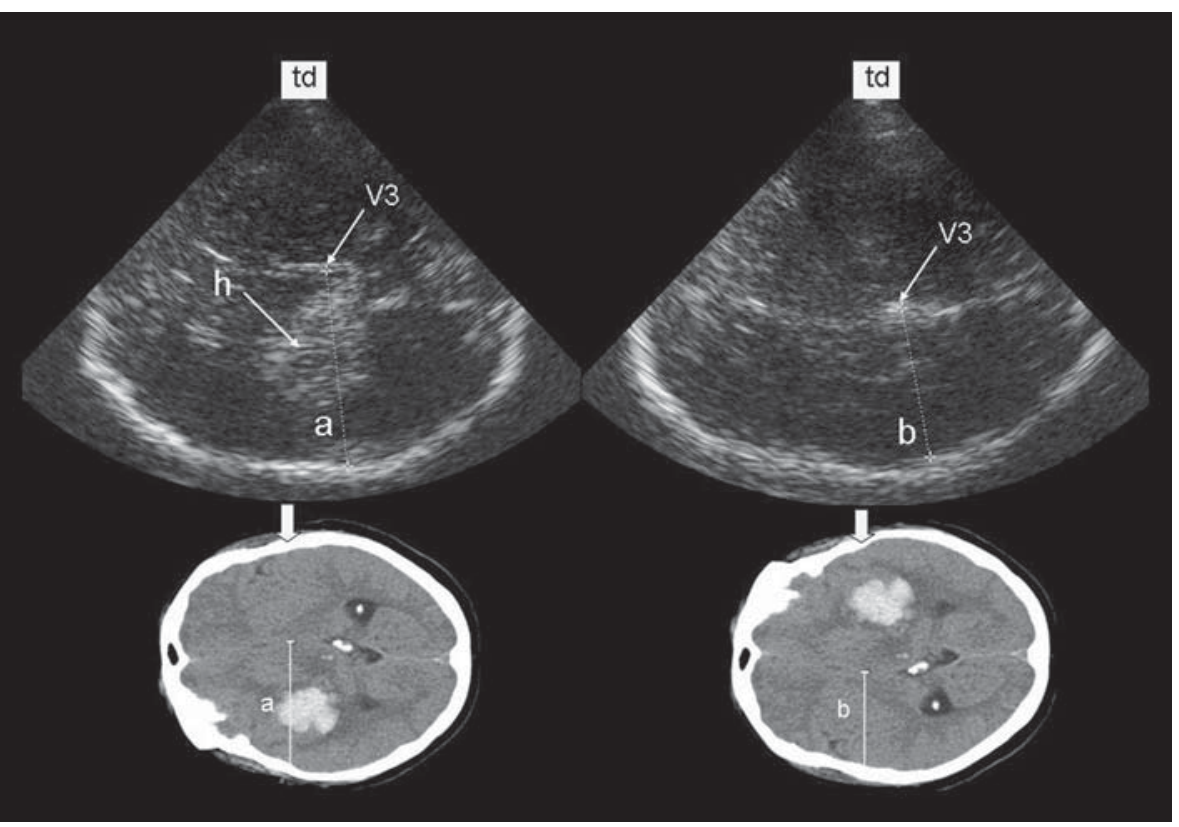

Fig. 1. Schematic illustration of MLS evaluated by TDS: insonation through the respective contralateral temporal bone window. Distances from the right (a) and left (b) tabulae of the skull to the third ventricle (V3). $\mathrm{h}=$ Hematoma; $\mathrm{td}=$ transducer.

Table 1. Demographic and clinical data of all patients and in each functional outcome group after 6 months

\begin{tabular}{|c|c|c|c|c|}
\hline Characteristics & All $(n=61)$ & $\mathrm{mRS} \leq 2(\mathrm{n}=5)$ & $\mathrm{mRS} \leq 4(\mathrm{n}=20)$ & $\mathrm{mRS}=6(\mathrm{n}=30)$ \\
\hline Age, years & $71(60-79)$ & $64(61-65)$ & $66(60-77)$ & $74(60-81)$ \\
\hline Gender, female & $23(37.8)$ & $2(40.0)$ & $8(40.0)$ & $12(40.0)$ \\
\hline Arterial hypertension & $35(57.4)$ & $3(60.0)$ & $11(55.0)$ & $19(63.3)$ \\
\hline Hyperlipidemia & $39(63.9)$ & $4(80.0)$ & $13(65.0)$ & $20(66.7)$ \\
\hline Diabetes mellitus & $14(22.9)$ & $1(20.0)$ & $5(25.0)$ & $7(23.3)$ \\
\hline LOV, days & $11(6-21)$ & $10(8-16)$ & $17(10-24)$ & $7(3-16)$ \\
\hline NIHSS at admission & $21 \pm 11$ & $7 \pm 6$ & $15 \pm 11$ & $26 \pm 11$ \\
\hline Hematoma volume, $\mathrm{cm}^{3}$ & $51.9 \pm 36.1$ & $24.8 \pm 8.6$ & $27.1 \pm 9.0$ & $76.1 \pm 38.2$ \\
\hline Hematoma localization (right) & $34(55.7)$ & $3(60.0)$ & $11(55.0)$ & $19(63.3)$ \\
\hline Ventricular involvement & $42(68.9)$ & $2(40.0)$ & $10(50.0)$ & $24(80.0)$ \\
\hline
\end{tabular}

Values are median (IQR), number (\%) or mean $\pm \mathrm{SD}$. LOV = Length of ventilation.

\section{Results}

\section{Patients and Baseline Characteristics}

Within a 1-year period, 68 patients with an ICH volume of $>20 \mathrm{~cm}^{3}$ were screened. Sixty-one of them fulfilled the inclusion criteria and provided consent to participate in this study ( 1 female patient provided insufficient temporal bone windows, 2 patients underwent hematoma evacuation and 4 had DNT/DNR status). The median NIHSS score upon admission was 21 and the mean hematoma volume was $52 \mathrm{~cm}^{3}$. The demographic and clinical data of the patients are given in table 1 . The parameters of baseline NIHSS score, $\mathrm{mRS}$ at 6 months after discharge, hematoma volume and MLS were correlated with one another in the examined patient cohort $(-0.3>r>0.3 ; p<0.05)$.

\section{Cut-Off Values of MLS for Impending Treatment}

Failure and Mortality

Table 2 gives the results of ROC analyses (specificity and sensitivity) and positive and negative predictive values (PPV and NPV) for critical values of MLS for each day (days 1-14), indicating death after 6 months. These data 
Fig. 2. MLS of each patient depending on time (days 1-14) and mortality [survival (white) vs. death (black)]. Cut-off values derived from ROC analyses that best predict mortality are drawn as horizontal lines at all time points.

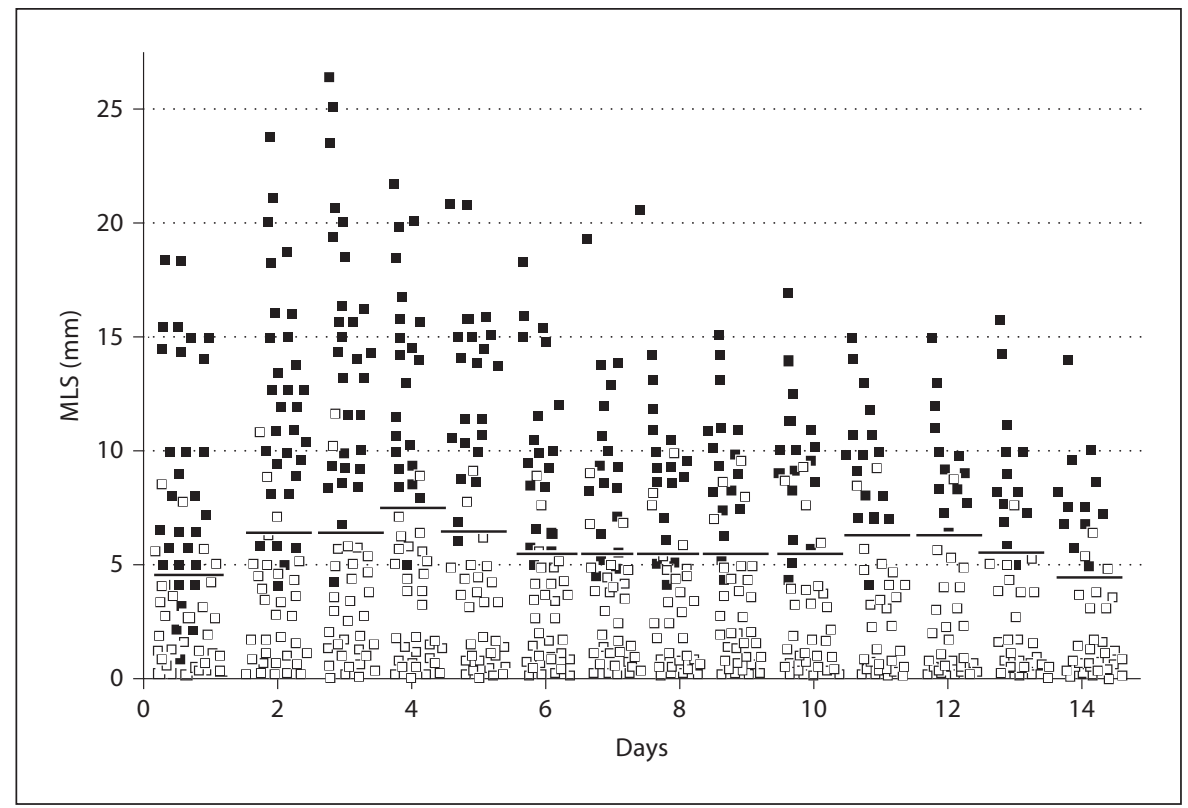

Table 2. Critical MLS derived from the ROC analyses: specificity, sensitivity, PPV and NPV of MLS for mortality after 6 months

\begin{tabular}{rllllllll}
\hline Day & MLS, mm & Sensitivity & Specificity & AUC & PPV & NPV & $n$ & p \\
\hline 1 & $>4.5$ & 0.714 & 0.828 & 0.874 & 83.3 & 77.4 & 61 & $<0.001$ \\
2 & $>6.5$ & 0.786 & 0.897 & 0.910 & 89.7 & 81.3 & 61 & $<0.001$ \\
3 & $>6.5$ & 0.786 & 0.897 & 0.900 & 87.5 & 86.2 & 60 & $<0.001$ \\
4 & $>7.5$ & 0.786 & 0.966 & 0.916 & 93.3 & 87.1 & 54 & $<0.001$ \\
5 & $>6.5$ & 0.857 & 0.897 & 0.937 & 84.4 & 82.8 & 53 & $<0.001$ \\
6 & $>5.5$ & 0.857 & 0.862 & 0.919 & 84.8 & 85.7 & 51 & $<0.001$ \\
7 & $>5.5$ & 0.714 & 0.862 & 0.897 & 80.6 & 76.7 & 49 & $<0.001$ \\
8 & $>5.5$ & 0.643 & 0.828 & 0.869 & 81.3 & 79.3 & 49 & $<0.001$ \\
9 & $>5.5$ & 0.714 & 0.828 & 0.837 & 81.3 & 76.7 & 48 & $<0.001$ \\
10 & $>5.5$ & 0.786 & 0.828 & 0.866 & 84.4 & 82.1 & 48 & $<0.001$ \\
11 & $>6.5$ & 0.857 & 0.931 & 0.897 & 87.1 & 83.3 & 47 & $<0.001$ \\
12 & $>6.5$ & 0.857 & 0.966 & 0.908 & 90.3 & 86.7 & 44 & $<0.001$ \\
13 & $>5.5$ & 0.786 & 0.966 & 0.894 & 90.0 & 84.4 & 43 & $<0.001$ \\
\end{tabular}

The second column gives the critical MLS (cut-off value) for the respective day after the ictus. The subsequent columns give the results of the ROC analyses of the critical MLS cut-off values. $n=$ Number of patients included in the respective analysis.

indicate that there was a cut-off value ranging between 4.5 and $7.5 \mathrm{~mm}$ (depending on the day) that differentiated between survival and death in patients who underwent conservative therapy (fig. 2). These values show two peaks, the first between day 2 and day 5 and the second on days $12-14$, indicating that in $\mathrm{ICH}$, edema growth progresses not only during the acute phase but also during the subacute phase. This is particularly distinctive in patients who did not survive the 6-month period after the ictus (fig. 3). An MLS of more than $12 \mathrm{~mm}$ at any given time indicated mortality with a sensitivity of $69 \%$, a specificity of $100 \%$, a PPV of $100 \%$ and an NPV of $74 \%$. The area under the curve (AUC) was 0.957. 


\section{Prediction of Outcome and Mortality}

To test the relevance of sonographic MLS measurements at different time points, logistic regression models correcting for relevant factors identified in univariate analysis were calculated. Results are given in table 3. Beside MLS at various time points, these analyses showed that ICH score on admission, ICH volume and absence of early hematoma growth were predictive of functional outcome. NIHSS score at admission showed a trend towards an association with outcome after 6 months, and ventricular extension of hemorrhage revealed a trend towards an association with unfavorable outcome and death.

\section{Detection of Early Hematoma Growth and Rapid Increase of Edema}

In 14 patients, an increase of MLS of $5 \mathrm{~mm}$ or more within $24 \mathrm{~h}$ was observed (median $6 \mathrm{~mm}$; IQR 5-6 mm). Upon follow-up CT, 3 of these patients (21\%) had hematoma growth $\geq 33 \%$ compared to the previous CT. No other patients exhibited hematoma growth during the study period. The sensitivity of this end point reached $100 \%$, but both the specificity and PPV for rebleeding were low. However, all 14 patients with an MLS increase $>5 \mathrm{~mm}$ within $24 \mathrm{~h}$ had an unfavorable outcome, and only 1 survived the first 6 months $(\mathrm{mRS}=5)$.

\section{Discussion}

Even though transcranial sonography, particularly the sonographic identification of midline structures, was among the first medical ultrasound applications [21], the advancement of other imaging modalities has since limited its use. This is mainly due to the typical drawbacks of TDS, which include examiner dependency, susceptibility to an insufficient temporal bone window, lower spatial resolution and possible artifacts. However, while these drawbacks may impede the use of TDS in certain clinical applications, the advantages of the method, including its bedside availability and the lack of radiation exposure, make TDS an ideal tool for other clinical situations that require frequent control examinations. The study did not aim to replace follow-up radiological examinations in this patient population, but to test whether daily serial TDS can serve as a complementary bedside screening method to identify individual patients with impending failure of maximal conservative neurointensive care treatment.

Detection and monitoring of MLS can easily be accomplished by TDS. Earlier studies revealed a high cor-

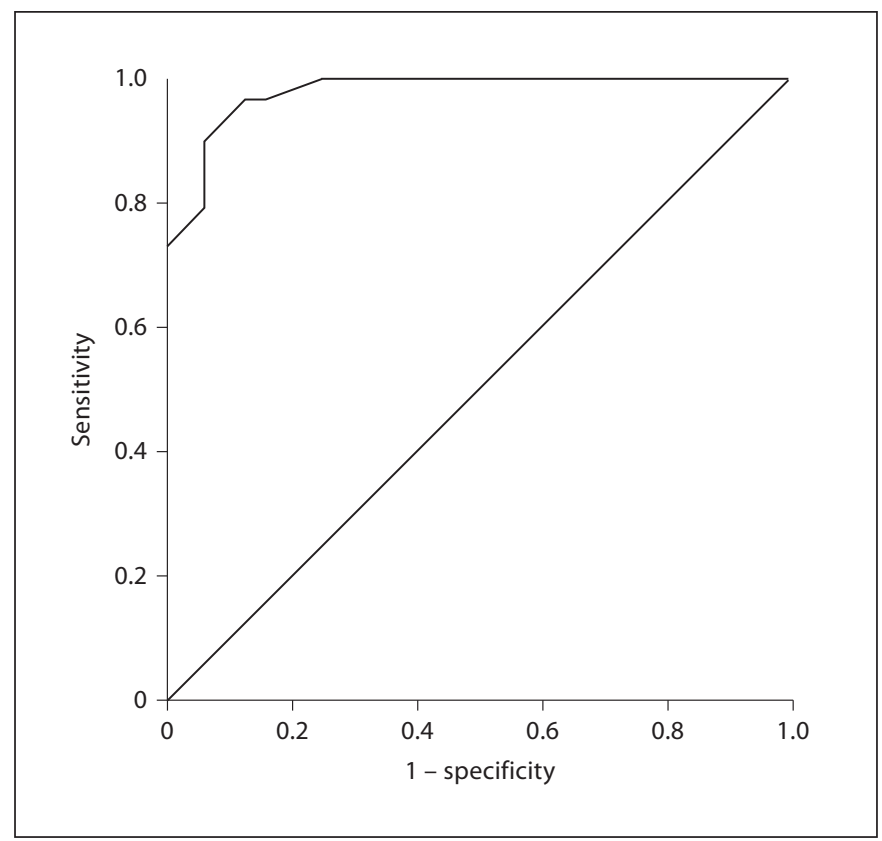

Fig. 3. ROC curve for worst MLS of each individual patient and mortality after 6 months. An MLS of $12 \mathrm{~mm}$ or greater indicated mortality with a sensitivity of $69 \%$, a specificity of $100 \%$ and a PPV and NPV of 100 and 74\%, respectively. The AUC was 0.957.

relation of the determination of the third ventricle between TDS and CT and a robust inter- and intraobserver reliability $[22,23]$. In addition to the monitoring of MLS, serial TDS examinations allow the assessment of lateral ventricular width, ventricular involvement of the ICH, monitoring of posthemorrhagic hydrocephalus and detection of early hematoma growth [11-13, 24].

MLS seems to be one of the most crucial factors for functional outcome after ICH [6]. Apart from the hematoma itself, vasogenic and cytotoxic brain edema add to the intracranial rise in volume, leading to increased intracranial pressure, tissue shift and, in severe cases, subsequent cerebral herniation. To identify patients at risk, early predictors of elevated intracranial pressure, such as incipient MLS, need to be included in the decision-making process. This can be accomplished by repeated CT scans or, more conveniently, by repeated bedside TDS. Tang et al. [13] observed a correlation among ICH volume, short-term functional outcome and MLS measured by TDS. This has been confirmed by Fogelholm et al. [25], who reported a correlation between MLS and mortality at 28 days. In our study, repeated TDS exhibited high correlations between MLS and functional status after 6 months. In contrast to the ICH score on admission, which 
Fig. 4. Box-plot of MLS on days 1-14 in patients who died within 6 months after ICH. Two peaks of MLS are found. The circles (days 1 and 14) indicate statistical outliers.

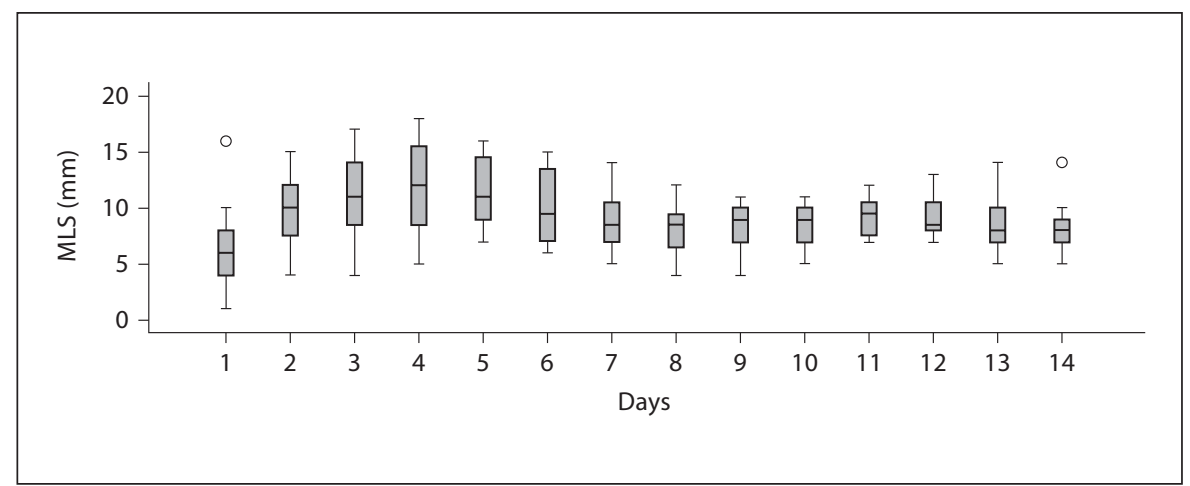

Table 3. Stepwise logistic regression models calculated for MLS on each day until day 14 depending on functional outcome after 6 months

\begin{tabular}{|c|c|c|c|c|c|c|c|c|c|}
\hline & \multicolumn{3}{|c|}{$m R S \leq 2(n=5)$} & \multicolumn{3}{|c|}{$\mathrm{mRS} \leq 4(\mathrm{n}=20)$} & \multicolumn{3}{|c|}{$\mathrm{mRS}=6(\mathrm{n}=30)$} \\
\hline & $\exp ($ coef) & $95 \% \mathrm{CI}$ & $\mathrm{p}$ value & $\exp ($ coef) & $95 \% \mathrm{CI}$ & $\mathrm{p}$ value & $\exp ($ coef) & $95 \% \mathrm{CI}$ & $\mathrm{p}$ value \\
\hline MLS day 1 & 0.43 & $0.17-1.02$ & 0.06 & 0.69 & $0.54-0.88$ & $<0.05$ & 1.53 & $1.21-1.97$ & $<0.05$ \\
\hline MLS day 2 & 0.39 & $0.16-0.94$ & $<0.05$ & 0.59 & $0.44-0.79$ & $<0.05$ & 1.88 & $1.37-2.59$ & $<0.05$ \\
\hline MLS day 3 & 0.24 & $0.06-0.99$ & $<0.05$ & 0.61 & $0.46-0.80$ & $<0.05$ & 1.97 & $1.38-2.47$ & $<0.05$ \\
\hline MLS day 4 & 0.30 & $0.08-1.19$ & 0.09 & 0.64 & $0.50-0.82$ & $<0.05$ & 2.90 & $1.31-6.03$ & $<0.05$ \\
\hline MLS day 5 & 0.12 & $0.02-1.04$ & 0.06 & 0.59 & $0.43-0.80$ & $<0.05$ & 2.69 & $1.31-5.51$ & $<0.05$ \\
\hline MLS day 6 & 0.17 & $0.02-1.28$ & 0.09 & 0.58 & $0.43-0.79$ & $<0.05$ & 2.41 & $1.35-4.21$ & $<0.05$ \\
\hline MLS day 7 & 0.13 & $0.02-1.18$ & 0.07 & 0.54 & $0.38-0.76$ & $<0.05$ & 2.21 & $1.41-3.49$ & $<0.05$ \\
\hline MLS day 8 & 0.17 & $0.02-1.31$ & 0.09 & 0.53 & $0.37-0.75$ & $<0.05$ & 1.87 & $1.30-2.78$ & $<0.05$ \\
\hline MLS day 9 & 0.19 & $0.03-1.20$ & 0.08 & 0.53 & $0.37-0.75$ & $<0.05$ & 1.63 & $1.26-2.18$ & $<0.05$ \\
\hline MLS day 10 & 0.13 & $0.01-1.22$ & 0.07 & 0.54 & $0.38-0.76$ & $<0.05$ & 2.01 & $1.32-2.97$ & $<0.05$ \\
\hline MLS day 11 & $\mathrm{n} / \mathrm{a}$ & $\mathrm{n} / \mathrm{a}$ & $\mathrm{n} / \mathrm{a}$ & 0.56 & $0.41-0.77$ & $<0.05$ & 2.36 & $1.41-3.77$ & $<0.05$ \\
\hline MLS day 12 & $\mathrm{n} / \mathrm{a}$ & $\mathrm{n} / \mathrm{a}$ & $\mathrm{n} / \mathrm{a}$ & 0.58 & $0.44-0.78$ & $<0.05$ & 4.24 & $1.23-14.61$ & $<0.05$ \\
\hline MLS day 13 & $\mathrm{n} / \mathrm{a}$ & $\mathrm{n} / \mathrm{a}$ & $\mathrm{n} / \mathrm{a}$ & 0.52 & $0.36-0.75$ & $<0.05$ & 3.45 & $1.40-8.45$ & $<0.05$ \\
\hline MLS day 14 & $\mathrm{n} / \mathrm{a}$ & $\mathrm{n} / \mathrm{a}$ & $\mathrm{n} / \mathrm{a}$ & 0.49 & $0.32-0.74$ & $<0.05$ & 4.24 & $1.36-13.18$ & $<0.05$ \\
\hline
\end{tabular}

The model corrected for age, sex, NIHSS at admission, pre-ICH mRS, ICH score, ICH volume, localization of ICH, ventricular hemorrhage and early hematoma growth. Significant parameters are expressed in bold. CI = Confidence interval; $\mathrm{n} / \mathrm{a}=$ not available.

also predicted long-term outcome, the advantage of such repeated measurements is that they allow for the identification of a clinical course for each specific patient instead of giving a statistical prognosis based on a single finding upon admission.

MLS differed significantly as early as day 1 between those patients who survived and those who died during the study period (table 2; fig. 2). Furthermore, ROC analyses defined a cut-off value for MLS ranging between 4.5 and $7.5 \mathrm{~mm}$, depending on the time point after $\mathrm{ICH}$, above which the chances for survival drastically decreased. As all enrolled patients received maximal con- servative but not surgical therapy, such as hematoma evacuation, these may be the cut-off values that indicate the impending failure of conservative strategies.

An MLS above $12 \mathrm{~mm}$ at any time during the clinical course had a PPV of $100 \%$ for a fatal outcome at 6 months. Data on MLS for the prediction of functional outcome in patients with ICH are sparse compared to patients with ischemic stroke. However, a number of publications report that increasing MLS negatively correlates with survival. However, most of the existing publications either correlate any MLS, regardless of its extent, to functional outcome [6], or correlate any MLS above $5 \mathrm{~mm}$ to mortal- 
ity $[25,26]$. Only one study, albeit one examining a cohort of ischemic stroke patients, defines specific critical values of MLS at several time points until $40 \mathrm{~h}$ after the ictus [14].

The critical MLS cut-off values that best predicted mortality after 6 months show two peaks indicating progressing edema growth not only during the acute phase but also during the subacute phase (fig. 4). This finding is supported by previously published data [27-29] and may also be explained by the observation that the first time point corresponds to the early phase of initial edema formation and the titration phase of treatment, while the second peak coincides with the usual phase for tapering antiedematous medication.

Previous studies using serial TDS examination to directly visualize the hematoma at early time points have shown that TDS can be used to reliably detect early hematoma growth [12]. In contrast, by measuring the increase of MLS within $24 \mathrm{~h}$, our method can only indirectly address this question by evaluating the dynamics of MLS evolution. A cut-off MLS increase of $>5 \mathrm{~mm}$ over $24 \mathrm{~h}$ identifies patients with rebleeding with a sensitivity of $100 \%$, although its specificity and PPV remain low. Thus, further CT scanning is indicated in this subgroup as defined by TDS and will identify all patients with early hematoma enlargement. In addition, even in the absence of rebleeding, such a rapid and dynamic increase of MLS defines a subgroup of patients with grim prognosis and no patient in this group can be expected to achieve an acceptable outcome.

It needs to be highlighted that all patients in this study received maximal conservative neurointensive therapy, including endovascular normothermia and antiedematous drugs, throughout the trial. Without these therapy strategies, lower MLS values might have been fatal. As previous studies have indicated that DNT/DNR orders themselves may be the reason for a grave prognosis [30, 31 , we felt that the inclusion of these patients $(n=4)$ might result in a change in cut-off MLS value and thus possibly lead to a reduction in neurological therapy in some patients with borderline MLS values who would otherwise have been treated differently. We therefore stress that the data in this study should not lead to the deprivation of neurointensive therapy in patients with increased MLS who are not undergoing maximal treatment.

There are limitations to our study, mainly involving the small patient number and the single-center design. However, with its focus on daily TDS examinations over the first 14 days, the study still includes 770 TDS exami- nations. Correlations of TDS with CT results and the inter- and intraobserver reliabilities of TDS were not assessed in our study because these aspects were evaluated in previous trials [32]. A recurrent limitation of TDS is an insufficient temporal bone window, which may be encountered especially in older female patients [33]; however, we only excluded 1 female patient on these grounds. Compared to other applications of TDS, identifying the prominent echogenic mid-line (3rd ventricle) is far less dependent on insonation windows. This is also illustrated by the fact that this application was feasible more than 50 years ago using much less sophisticated techniques $[34,35]$.

\section{Conclusion}

Our data suggest that serial TDS examinations of MLS may be used to monitor intensive-care treatment and to predict functional outcome and mortality in patients with supratentorial ICH. The method does not aim to replace standard diagnostics (e.g. follow-up CT scans) but offers a complementary noninvasive bedside screening method, which enables the treating physician to identify patients with impending failure of maximal intensivecare management. However, as this study was single-centered and based on a relatively small number of patients, further studies to confirm the data are required.

References

Cerebrovasc Dis 2012;34:297-304
Bamford J, Sandercock P, Dennis M, Burn J, Warlow C: A prospective study of acute cerebrovascular disease in the community: the Oxfordshire Community Stroke Project-1981-86. 2. Incidence, case fatality rates and overall outcome at one year of cerebral infarction, primary intracerebral and subarachnoid haemorrhage. J Neurol Neurosurg Psychiatry 1990;53:16-22.

2 Broderick JP, Brott TG, Duldner JE, Tomsick T, Huster G: Volume of intracerebral hemorrhage. A powerful and easy-to-use predictor of 30-day mortality. Stroke 1993;24:987993.

- 3 Stead LG, Jain A, Bellolio MF, Odufuye A, Gilmore RM, Rabinstein A, Chandra R, Dhillon R, Manivannan V, Serrano LA, Yerragondu N, Palamari B, Jain M, Decker WW: Emergency department hyperglycemia as a predictor of early mortality and worse functional outcome after intracerebral hemorrhage. Neurocrit Care 2010;13:67-74. 
4 Tuhrim S, Horowitz DR, Sacher M, Godbold $\mathrm{JH}$ : Volume of ventricular blood is an important determinant of outcome in supratentorial intracerebral hemorrhage. Crit Care Med 1999;27:617-621.

$\checkmark 5$ Vermeer SE, Algra A, Franke CL, et al: Longterm prognosis after recovery from primary intracerebral hemorrhage. Neurology 2002; 59:205-209.

-6 Hallevy C, Ifergane G, Kordysh E, Herishanu Y: Spontaneous supratentorial intracerebral hemorrhage. Criteria for short-term functional outcome prediction. J Neurol 2002; 249:1704-1709.

7 Bercault N, Wolf M, Runge I, Fleury JC, Boulain T: Intrahospital transport of critically ill ventilated patients: a risk factor for ventilator-associated pneumonia - a matched cohort study. Crit Care Med 2005;33:24712478.

$>8$ Voigt LP, Pastores SM, Raoof ND, Thaler HT, Halpern NA: Review of a large clinical series. Intrahospital transport of critically ill patients: outcomes, timing, and patterns. J Intensive Care Med 2009;24:108-115.

$\checkmark 9$ Waydhas C: Intrahospital transport of critically ill patients. Crit Care 1999;3:R83-R89.

-10 Schlachetzki F, Herzberg M, Hölscher T, Ertl M, Zimmermann M, Ittner KP, Pels H, Bogdahn U, Boy S: Transcranial ultrasound from diagnosis to early stroke treatment. 2 . Prehospital neurosonography in patients with acute stroke: the Regensburg Stroke Mobile Project. Cerebrovasc Dis 2012;33: 262-271.

-11 Meyer-Wiethe K, Sallustio F, Kern R: Diagnosis of intracerebral hemorrhage with transcranial ultrasound. Cerebrovasc Dis 2009; 27(suppl 2):40-47.

- 12 Perez ES, Delgado-Mederos R, Rubiera M, Delgado P, Ribó M, Maisterra O, Ortega G, Alvarez-Sabin J, Molina CA: Transcranial duplex sonography for monitoring hyperacute intracerebral hemorrhage. Stroke 2009;40:987-990.

-13 Tang SC, Huang SJ, Jeng JS, Yip PK: Third ventricle midline shift due to spontaneous supratentorial intracerebral hemorrhage evaluated by transcranial color-coded sonography. J Ultrasound Med 2006;25:203209.

14 Gerriets T, Stolz E, Konig S, Babacan S, Fiss I, Jauss M, Kaps M: Sonographic monitoring of midline shift in space-occupying stroke: an early outcome predictor. Stroke 2001;32: 442-447.
15 Steiner T, Kaste M, Forsting M, Mendelow D, Kwiecinski H, Szikora I, Juvela S, Marchel A, Chapot R, Cognard C, Unterberg A, Hacke $\mathrm{W}$ : Recommendations for the management of intracranial haemorrhage. I. Spontaneous intracerebral haemorrhage. The European Stroke Initiative Writing Committee and the Writing Committee for the EUSI Executive Committee. Cerebrovasc Dis 2006;22:294316.

16 Kothari RU, Brott T, Broderick JP, Barsan WG, Sauerbeck LR, Zuccarello M, Khoury J: The ABCs of measuring intracerebral hemorrhage volumes. Stroke 1996;27:1304-1305.

17 Brott T, Broderick J, Kothari R, Barsan W, Tomsick T, Sauerbeck L, Spilker J, Duldner J, Khoury J: Early hemorrhage growth in patients with intracerebral hemorrhage. Stroke 1997;28:1-5.

18 Merino JG, Lattimore SU, Warach S: Telephone assessment of stroke outcome is reliable. Stroke 2005;36:232-233.

19 Kiphuth IC, Köhrmann M, Kuramatsu JB, Mauer C, Breuer L, Schellinger PD, Schwab S, Huttner HB: Retrospective agreement and consent to neurocritical care is influenced by functional outcome. Crit Care 2010;14:R144.

-20 Kiphuth IC, Kohrmann M, Lichy C, Schwab S, Huttner HB: Hemicraniectomy for malignant middle cerebral artery infarction: retrospective consent to decompressive surgery depends on functional long-term outcome. Neurocrit Care 2010;13:380-384.

21 Dussik KT, Dussik F, Wyt L: Auf dem Wege zur Hyperphonographie des Gehirnes. Wien Med Wochenschr 1947;97:425-429.

22 Becker G, Bogdahn U, Strassburg HM, Lindner A, Hassel W, Meixensberger J, Hofmann E: Identification of ventricular enlargement and estimation of intracranial pressure by transcranial color-coded real-time sonography. J Neuroimaging 1994;4:17-22.

23 Seidel G, Kaps M, Gerriets T, Hutzelmann A: Evaluation of the ventricular system in adults by transcranial duplex sonography. J Neuroimaging 1995;5:105-108.

24 Kiphuth IC, Huttner HB, Struffert T, Schwab S, Kohrmann M: Sonographic monitoring of ventricle enlargement in posthemorrhagic hydrocephalus. Neurology 2011;76:858-862.
25 Fogelholm R, Murros K, Rissanen A, Avikainen S: Long term survival after primary intracerebral haemorrhage: a retrospective population based study. J Neurol Neurosurg Psychiatry 2005;76:1534-1538.

26 Daverat P, Castel JP, Dartigues JF, Orgogozo JM: Death and functional outcome after spontaneous intracerebral hemorrhage. A prospective study of 166 cases using multivariate analysis. Stroke 1991;22:1-6.

27 Olivot JM, Mlynash M, Kleinman JT, Straka $\mathrm{M}$, Venkatasubramanian $\mathrm{C}$, Bammer R, Moseley ME, Albers GW, Wijman CA; DASH investigators: MRI profile of the perihematomal region in acute intracerebral hemorrhage. Stroke 2010;41:2681-2683.

28 Rosenberg GA: Ischemic brain edema. Prog Cardiovasc Dis 1999;42:209-216.

-29 Venkatasubramanian C, Mlynash M, Finley-Caulfield A, Eyngorn I, Kalimuthu R, Snider RW, Wijman CA: Natural history of perihematomal edema after intracerebral hemorrhage measured by serial magnetic resonance imaging. Stroke 2011;42:73-80.

30 Becker KJ, Baxter AB, Cohen WA, Bybee HM, Tirschwell DL, Newell DW, Winn HR, Longstreth WT Jr: Withdrawal of support in intracerebral hemorrhage may lead to selffulfilling prophecies. Neurology 2001;56: 766-772.

31 Creutzfeldt CJ, Becker KJ, Weinstein JR, Khot SP, McPharlin TO, Ton TG, Longstreth WT Jr: Do-not-attempt-resuscitation orders and prognostic models for intraparenchymal hemorrhage. Crit Care Med 2011;39:158162.

-32 Seidel G, Kaps M, Gerriets T, Hutzelmann A: Evaluation of the ventricular system in adults by transcranial duplex sonography. J Neuroimaging 1995;5:105-108.

-33 Krejza J, Swiat M, Pawlak MA, Oszkinis G, Weigele J, Hurst RW, Kasner S: Suitability of temporal bone acoustic window: conventional TCD versus transcranial color-coded duplex sonography. J Neuroimaging 2007;17: 311-314.

34 Jeppsson S: Echoencephalography. III. Further studies on the sources of the midline echo and a clinical evaluation. Acta Chir Scand 1960;119:455-462.

35 Leksell L: Echo-encephalography. I. Detection of intracranial complications following head injury. Acta Chir Scand 1956;110:301315 . 